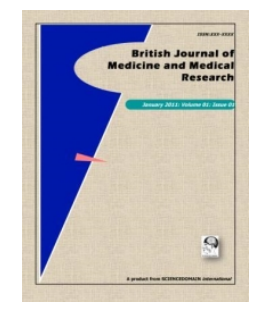

British Journal of Medicine \& Medical Research

3(1): 49-57, 2013

SCIENCEDOMAIN international

www.sciencedomain.org

\title{
Assessment of Polycystic Ovarian Syndrome Patients' Perception for Different Cardiovascular Risk Factors using Questionnaire
}

\author{
Antoaneta Gateva $^{1^{*}}$ and Zdravko Kamenov ${ }^{1}$ \\ ${ }^{1}$ Clinic of endocrinology, University Hospital Alexandrovska, Medical University-Sofia, \\ Bulgaria.
}

Authors' contributions

This work was carried out in collaboration between all authors. Author AG managed literature searches, managed the analysis of the study, performed the statistical analysis and wrote the first draft of the manuscript. Author ZK designed the study and wrote the protocol, and wrote the first draft of the manuscript. All authors read and approved the final

manuscript.

Research Article

Received $18^{\text {th }}$ August 2012

Accepted $16^{\text {th }}$ October 2012

Published 8 ${ }^{\text {th }}$ December 2012

\section{ABSTRACT}

Aim: The aim of the present study was to investigate the perception for the presence of cardiovascular risk factors in Bulgarian patients with PCOS and/or obesity.

Study Design: Clinic of endocrinology, Alexandrovska University Hospital, Sofia, Bulgaria between January 2010 and December 2011.

Methodology: One hundred women (30 obese, 50 nonobese PCOS and 20 obese PCOS) aged 18-45 years were included in the study. They were asked to fill a questionnaire, containing questions about common and popular cardiovascular risk factors like obesity, arterial hypertension, dislipidemia, diabetes and stress. Then their answers were compared to the results form the anthropometric measurements and laboratory tests, performed during the hospital stay.

Results: $98 \%$ of the patients with body mass index $\geq 30 \mathrm{~kg} / \mathrm{m}^{2}$ stated that they have obesity and do not find their weight appropriate. Only 33.3\% of the obese PCOS patients however were able to point their present weight correctly, compared to $59.3 \%$ in obese and $67.3 \%$ in nonobese PCOS patients group. $56.7 \%$ of obese and $65 \%$ of obese PCOS 
patients stated that they were treated for obesity (diet, physical activity or drugs). 59,3\% of obese patients had dislipidemia without knowing that while the actual rate of dislipidemia in this group was $70 \%$. The highest matching between the answers of the patients and the test results was observed for arterial hypertension $-82.1 \%, 96.0 \%$ and $84.2 \%$ for obese, nonobese PCOS and obese PCOS groups respectively. The data about the presence of stress at home or at work showed that women with PCOS have generally higher rates of stress compared to obese women without PCOS.

Conclusion: Patients with PCOS and/or obesity are well informed about the presence of the common cardiovascular risk factors.

Keywords: Polycystic ovarian syndrome; obesity; cardiovascular risk; patients' perception.

\section{INTRODUCTION}

Polycystic ovarian syndrome (PCOS) is one of the most common endocrine disturbances in women (about $6-10 \%$ in reproductive age) and is linked to most of the cases of hirsutism, menstrual disturbances and anovulatory infertility $[1,2,3]$.

Besides the well known reproductive and aesthetic consequences of PCOS, patients with the syndrome have a higher rate of some cardiovascular and metabolic risk factors like diabetes, hypertension, dislipidemia and increased waist-to-hip ratio. Using a risk factor model it has been shown that PCOS patients have 4 to 7 times higher risk for myocardial infarction compared to age matched healthy controls [4]. Further it has been found that PCOS patients have higher risk for type 2 diabetes [5,6,7]. Identification of the clinical characteristics of the syndrome assumes increased cardiovascular risk and should be followed by assessment of separate risk factors.

The modern treatment of PCOS is noninvasive and is very different form the approaches used 20-30 years ago. It implies causal effect on the underlying metabolic disturbances by insulin sensitizing agents and ovarian suppression. Complex treatment can be effective in normalizing patients' weight, optimizing the metabolic profile, reducing skin manifestations of hyperandrogenemia and overcoming subfertility.

The success of any treatment and prophylaxis depends on two main factors - professional competence of medical specialists and patients' compliance. On the other hand patients' compliance is formed by the knowledge of the health issue and the motivation to be treated. Recognition of the problem is the first step towards its solution. Because of the high prevalence of PCOS and hence high social importance, patient education has high priority for cardiovascular disease prevention.

Our goal was to investigate this particular aspect of prevention and treatment of cardiovascular diseases in PCOS patients using a questionnaire, focused on the most important and in the same time most common cardiovascular risk factors like obesity, hypertension, dislipidemia, diabetes and stress.

\section{MATERIALS AND METHODS}

In the present study were included patients with PCOS and/or obesity.

The following inclusion and exclusion criteria were used: 
Inclusion criteria

- $\quad$ premenopausal women aged 18 to 45

- PCOS, diagnosed by ESHRE-ASRM criteria or

- $\quad B M I \geq 30 \mathrm{~kg} / \mathrm{m}^{2}$

Exclusion criteria

- Pregnancy

- Serious illnesses as cardiac, renal or liver insufficiency

- Other endocrine pathology like type 2 diabetes mellitus, adrenal tumors, hypothyroidism, prolactinomas, hypogonadism, Cushing's disease, congenital adrenal hyperplasia.

- Insulin sensitizing medication (metformin or glitazones) or combined oral contraceptive (COC, containing etinylestradiol and progestin) use less than 4 months prior to the study

The following information for each patient was obtained:

1. General information - name, age

Before starting the following procedures the patients that were included in the study filled a questionnaire with questions evaluating their awareness and self-perception about familiar to wide public risk factors for cardiovascular diseases like hypertension, dislipidemia, obesity, smoking and family history for such diseases and information regarding menstrual history and hirsutism.

2. Anthropometric data - height, weight, body mass index (BMI), waist, hip, waist-to-hip ratio (WHR), waist-to-stature ratio (WSR). All measurements were performed when the patients were in a standing position with feet together, relaxed abdomen and arms at their sides. Waist circumference of subjects was measured in standing position by placing a soft tape measure midway between the lowest rib and the iliac crest and hip circumference was measured at the level of the great trochanters.

3. Obesity was diagnosed at $B M \geq 30 \mathrm{~kg} / \mathrm{m}^{2}$.

4. Polycystic ovary syndrome was diagnosed according to the ESHRE-ASRM criteria- two out of the following: 1) oligo/amenorrhea; 2) clinical or biochemical hyperandrogenism and 3) polycystic ovaries at ultrasound examination when all other endocrine causes are excluded [8].

5. Arterial hypertension was diagnosed if the patient took antihypertensive treatment and/or arterial blood pressure (BP) measured during the hospital stay was $\geq 140 / 90 \mathrm{mmHg}$. The duration of the hypertension, present blood pressure - systolic (SBP) and diastolic (DBP), number and type of antihypertensive medications were also recorded. Blood pressure was measured on the right arm, with the subjects in a sitting position and relaxed.

6. Lipid profile - Total cholesterol (TC), HDL-cholesterol (HDL), LDL-cholesterol (LDL), VLDL-cholesterol, triglycerides (TG). Dislipidemia was diagnosed if there was any treatment for dislipidemia and/or measured during the hospital stay TC $>5.2 \mathrm{mmol} / \mathrm{l}$, and/or $\mathrm{HDL}<1.3$ $\mathrm{mmol} / \mathrm{l}$ and/or TG $\geq 1.8 \mathrm{mmol} / \mathrm{l}$. The duration of the dislipidemia, present lipid profile, type of treatment and number of medications were also recorded. 
7. Results form the oral glucose tolerance test (OGTT) - blood glucose and imunoreactive insulin (IRI) on 0, 60 and $120 \mathrm{~min}$. Homeostatic model assessment (HOMA-IR) was calculated as fasting blood glucose $(\mathrm{mmol} / \mathrm{l}) \mathrm{x}$ fasting $\mathrm{IRI}(\mathrm{mU} / \mathrm{l}) / 22.5$.

8. Hormonal status (testosterone, androstendione, dehydroepiandrosteron sulphate (DHEAS), 17- -progesterone, estradiol, LH, FSH, TSH, prolactin). If necessary, all other routine tests were performed to exclude other endocrine pathology as mentioned in the exclusion criteria.

We assessed patients' knowledge of the presence of these risk factors and the matching between the answers and the results form the instrumental and laboratory tests.

The data were processed using the statistical package SPSS 16.0, IBM. The level of significance for rejecting the null hypothesis was $p<0.05$. The following statistical methods were applied: descriptive analysis, variation analysis, Kolmogorov- Smirnov's one sample non-parametric test, Student's t-test for two independent samples, Kruskal-Wallis' nonparametric test for several independent samples, Mann-Whitney's non-parametric test for two independent samples, one-way analysis of variance between-groups ANOVA with posthoc tests. Data are presented as mean $\pm S D$.

\section{RESULTS AND DISCUSSION}

In the present study were included 100 patients divided into three groups - group 1 Obese $(\mathrm{n}=30)$; group 2 Nonobese PCOS $(\mathrm{n}=50)$ and group 3 Obese PCOS $(\mathrm{n}=20)$. Comparison was made between the data form these three groups. Anthropometric characteristics are shown on Table 1.

Table 1. Anthropometric characteristics of the groups

\begin{tabular}{|c|c|c|c|}
\hline & $\begin{array}{l}\text { Group } 1 \\
\text { Obese }(n=30)\end{array}$ & $\begin{array}{l}\text { Group } 2 \\
\text { Nonobese PCOS }(n=50)\end{array}$ & $\begin{array}{l}\text { Group } 3 \\
\text { Obese PCOS }(n=20)\end{array}$ \\
\hline Age (years) & $32.8 \pm 8.2^{\wedge \wedge \wedge}$ & $24.0 \pm 5.06$ & $25.1 \pm 4.8 \# \# \#$ \\
\hline Weight (kg) & $111.7 \pm 28.4^{\wedge \wedge \wedge}$ & $61.3 \pm 10.4^{\star * *}$ & $97.6 \pm 16.6 \#$ \\
\hline $\operatorname{BMI}\left(\mathrm{kg} / \mathrm{m}^{2}\right)$ & $41.7 \pm 9.9^{\wedge \wedge \wedge}$ & $22.6 \pm 3.3^{* \star *}$ & $36.2 \pm 6.1(p=.020)$ \\
\hline WHR & $0.89 \pm 0.08^{\wedge \wedge \wedge}$ & $0.79 \pm 0.06^{\star * *}$ & $0.88 \pm 0.09$ \\
\hline WSR & $0.70 \pm 0.09^{\wedge \wedge \wedge}$ & $0.47 \pm 0.06^{\star * \star}$ & $0.64 \pm 0.09(p=.024)$ \\
\hline
\end{tabular}

Patients with obesity without PCOS had significantly higher mean age, weight, BMI and WSR compared to the other two groups. The data from the questionnaire regarding body weight and height and matching to the real measurements are shown on Table 2. 
able 2. Body weight and height

\begin{tabular}{|c|c|c|c|}
\hline \multicolumn{4}{|l|}{ Do you have obesity? } \\
\hline & $\begin{array}{l}\text { Group } 1 \\
\text { Obese }\end{array}$ & $\begin{array}{l}\text { Group } 2 \\
\text { Nonobese PCOS }\end{array}$ & $\begin{array}{l}\text { Group } 3 \\
\text { Obese PCOS }\end{array}$ \\
\hline Yes & $96.7 \%$ & $22.0 \%^{* * *}$ & $100 \%$ \\
\hline No & $3.3 \%$ & $78.0 \%$ & 0 \\
\hline I don't know & 0 & 0 & 0 \\
\hline \multicolumn{4}{|c|}{ Since when do you have obesity? } \\
\hline Since childhood & $36.7 \%$ & $6 \%$ & $25 \%$ \\
\hline Since puberty & $23.3 \%$ & $10 \%$ & $30 \%$ \\
\hline Since childbirth & $36.7 \%$ & $0 \%$ ** & $30 \%$ \\
\hline \multicolumn{4}{|c|}{ Did you receive treatment for obesity? } \\
\hline With diet & $56.7 \%$ & $16 \%$ ** & $65 \%$ \\
\hline With physical activity & $30 \%$ & $20 \%$ & $45 \%$ \\
\hline With mediacation & $13.3 \%$ & $2 \%$ & $5 \%$ \\
\hline \multicolumn{4}{|l|}{ What is your current weight? } \\
\hline I don't know & $10.0 \%$ & $2.0 \%$ & $25 \%$ \\
\hline \multicolumn{4}{|c|}{ Do you think that your current weight is appropriate for you? } \\
\hline Yes & $3.3 \%$ & $52.0 \%{ }^{* * *}$ & 0 \\
\hline No & $96.7 \%$ & $42.0 \%$ & $100 \%$ \\
\hline I don't know & 0 & $6.0 \%$ & \\
\hline \multicolumn{4}{|c|}{ Difference between the declared and real weight } \\
\hline $0 \mathrm{~kg}=\mathrm{real}$ & $16(59.3 \%)$ & $33(67.3 \%)$ & $5(33.3 \%)$ \\
\hline$-7 \mathrm{~kg}$ & $1(3.7 \%)$ & 0 & 0 \\
\hline$-6 \mathrm{~kg}$ & 0 & $1(2 \%)$ & 0 \\
\hline$-5 \mathrm{~kg}$ & 0 & $1(2 \%)$ & 0 \\
\hline$-3 \mathrm{~kg}$ & 0 & $1(2 \%)$ & 0 \\
\hline$-2 \mathrm{~kg}$ & 0 & $1(2 \%)$ & $3(20 \%)$ \\
\hline$-1 \mathrm{~kg}$ & $3(11.1 \%)$ & $6(12.2 \%)$ & $3(20 \%)$ \\
\hline Total less than the real weight & $4(14.8 \%)$ & $10(20.4 \%)$ & $6(40 \%)$ \\
\hline$+1 \mathrm{~kg}$ & $3(11.1 \%)$ & $4(8.2 \%)$ & $1(6.7 \%)$ \\
\hline$+2 \mathrm{~kg}$ & $1(3.7 \%)$ & $1(2 \%)$ & $1(6.7 \%)$ \\
\hline$+3 \mathrm{~kg}$ & $1(3.7 \%)$ & 0 & 0 \\
\hline$+6 \mathrm{~kg}$ & 0 & 0 & $2(12.3 \%)$ \\
\hline$+7 \mathrm{~g}$ & 0 & $1(2 \%)$ & 0 \\
\hline$+8 \mathrm{~kg}$ & $1(3.7 \%)$ & 0 & 0 \\
\hline$+14 \mathrm{~kg}$ & $1(3,7 \%)$ & 0 & 0 \\
\hline Total more than the real weight & $7(25.9 \%)$ & $6(12.3 \%)$ & $426.7 \%)$ \\
\hline \multicolumn{4}{|c|}{ Difference between the declared and the real height } \\
\hline $0 \mathrm{~cm}$ & $11(42.3 \%)$ & $29(59.2 \%)^{\star}$ & $3(18.6 \%)$ \\
\hline$-3 \mathrm{~cm}$ & 0 & 0 & $1(6.2 \%)$ \\
\hline$-2 \mathrm{~cm}$ & 0 & $1(2 \%)$ & $1(6.2 \%)$ \\
\hline$-1 \mathrm{CM}$ & $3(11.5 \%)$ & $1(2 \%)$ & $1(6.2 \%)$ \\
\hline Total less than real height & $3(11.5 \%)$ & $2(4.1 \%)$ & $3(18.6 \%)$ \\
\hline$+1 \mathrm{cM}$ & $6(23.1 \%)$ & $3(6.1 \%)$ & $4(25 \%)$ \\
\hline$+2 \mathrm{~cm}$ & $1(3.8 \%)$ & $6(12.2 \%)$ & $2(12.5 \%)$ \\
\hline$+3 \mathrm{~cm}$ & $2(7.7 \%)$ & $6(12.2 \%)$ & $2(12.5 \%)$ \\
\hline$+4 \mathrm{~cm}$ & $1(3.8 \%)$ & $1(2 \%)$ & 0 \\
\hline$+5 \mathrm{~cm}$ & $1(3.8 \%)$ & $1(2 \%)$ & 0 \\
\hline$+6 \mathrm{cM}$ & $1(3.8 \%)$ & $1(2 \%)$ & $1(6.2 \%)$ \\
\hline$+7 \mathrm{~cm}$ & 0 & 0 & $1(6.2 \%)$ \\
\hline Total more than the real height & $12(46.2 \%)$ & $18(36.7 \%)$ & $10(62.8 \%)$ \\
\hline
\end{tabular}


Almost all of the patients with obesity have answered that they are obese and do not think that their current weight is appropriate for them. It is interesting to note that many of the nonobese patients did not think their weight is appropriate although most of them had $\mathrm{BMI}<$ $25 \mathrm{~kg} / \mathrm{m}^{2}$. After comparing the declared by the patients weight with the actual measured by the investigators weight we found the highest rate of matching $(67.3 \%)$ in the nonobese PCOS group and the lowest (33.3\%) - in the obese PCOS patients group. Among the obese women without PCOS this rate was $59.3 \%$.

Regarding the difference between the declared and the real height however there was a tendency towards higher declared height than the actual in the three groups. The highest rate of matching was found in nonobese PCOS patients group $-59.2 \%$ vs. obese women without PCOS $-423 \%$ and obese PCOS patients $-18.6 \%$.

The highest rate of matching between the real dislipidemia status and the reported by patients dislipidemia was found in nonobese PCOS group - $80 \%$ vs. $63.2 \%$ in obese PCOS and $33.3 \%$ in obese without PCOS groups. $59.3 \%$ of the women with obesity without PCOS have dislipidemia without knowing that, while this percent is lower with PCOS being diagnosed. The real rate of dislipidemia in patients with obesity is $70 \%$ (Table 3 ).

able 3. Dislipidemia

\begin{tabular}{|c|c|c|c|c|c|c|}
\hline \multicolumn{7}{|c|}{ Do you have high levels of lipids in the blood? } \\
\hline & \multicolumn{2}{|c|}{$\begin{array}{l}\text { Group } 1 \\
\text { Obese }\end{array}$} & \multicolumn{2}{|c|}{$\begin{array}{l}\text { Group } 2 \\
\text { Nonobese PCOS }\end{array}$} & \multicolumn{2}{|c|}{$\begin{array}{l}\text { Group } 3 \\
\text { Obese Pcos }\end{array}$} \\
\hline & perception & real & perception & real & perception & real \\
\hline Yes & $13.3 \%$ & $70.0 \%$ & $6.0 \%$ & $23.4 \%$ & $10.0 \%$ & $47.4 \%$ \\
\hline No & $76.7 \%$ & $30.0 \%$ & $90.0 \%$ & $76.6 \%$ & $90.0 \%$ & $52.6 \%$ \\
\hline I don't know & $10.0 \%$ & - & $4.0 \%$ & - & 0 & - \\
\hline \multicolumn{7}{|c|}{ What is you cholesterol level? } \\
\hline I don't know & $93.3 \%$ & & $90.0 \%$ & & $95.0 \%$ & \\
\hline \multicolumn{7}{|c|}{ Difference between the declared and the real lipid status } \\
\hline Match & $33.3 \%$ & & $80.0 \%{ }^{\star *}$ & & $63.2 \%$ & \\
\hline $\begin{array}{l}\text { Patient really } \\
\text { has } \\
\text { dislipidemia, } \\
\text { but thinks she } \\
\text { doesn't }\end{array}$ & $59.3 \%$ & & $17.8 \%$ & & $36.8 \%$ & \\
\hline $\begin{array}{l}\text { Patient really } \\
\text { doesn't have } \\
\text { dislipidemia, } \\
\text { but thinks she } \\
\text { does }\end{array}$ & $7.4 \%$ & & $2.2 \%$ & & $0 \%$ & \\
\hline
\end{tabular}

The highest rate of matching between the answers from the questionnaire and the real status was found for hypertension status $-82.1 \%, 96.0 \%$ and $84.2 \%$ in the three groups respectively (Table 4). It is interesting that more patients have stated that they have hypertension while they really didn't have than vice versa. 
able 4. Arterial hypertension

\begin{tabular}{|c|c|c|c|c|c|c|}
\hline \multicolumn{7}{|c|}{ Do you have hypertension? } \\
\hline & \multicolumn{2}{|l|}{$\begin{array}{l}\text { Group } 1 \\
\text { Obese }\end{array}$} & \multicolumn{2}{|c|}{$\begin{array}{l}\text { Group } 2 \\
\text { Nonobese PCOS }\end{array}$} & \multicolumn{2}{|c|}{$\begin{array}{l}\text { Group } 3 \\
\text { Obese PCOS }\end{array}$} \\
\hline & perception & real & perception & real & perception & real \\
\hline Yes & $36.7 \%$ & $26.7 \%$ & $6.0 \% \%^{\star \star}$ & $2.0 \%$ & $25.0 \%$ & $15.0 \%$ \\
\hline No & $56.7 \%$ & $73.3 \%$ & $94.0 \%$ & $98.0 \%$ & $70.0 \%$ & $85.0 \%$ \\
\hline I don't know & $6.6 \%$ & - & 0 & - & $5.0 \%$ & - \\
\hline \multicolumn{7}{|c|}{ Difference between the declared and real hypertension status } \\
\hline Match & $82.1 \%$ & & $96.0 \%$ & & $84.2 \%$ & \\
\hline $\begin{array}{l}\text { Patient has } \\
\text { hypertension } \\
\text { but thinks she } \\
\text { doesn't }\end{array}$ & $3.3 \%$ & & 0 & & 0 & \\
\hline $\begin{array}{l}\text { Patients doesn't } \\
\text { have } \\
\text { hypertension } \\
\text { but thinks she } \\
\text { does }\end{array}$ & $13.3 \%$ & & $4.0 \%$ & & $15.8 \%$ & \\
\hline \multicolumn{7}{|c|}{ What is your usual blood pressure? } \\
\hline I don't know & $23.3 \%$ & & $52 \%$ & & $30 \%$ & \\
\hline \multicolumn{7}{|c|}{ Do you think that this blood pressure is appropriate for you? } \\
\hline Yes & $56.7 \%$ & & $34 \%$ & & $55 \%$ & \\
\hline No & $16.7 \%$ & & $16 \%$ & & $15 \%$ & \\
\hline I don't know & $26.6 \%$ & & $50 \%$ & & $30 \%$ & \\
\hline
\end{tabular}

The data about the presence of stress on the workplace and at home showed that nonobese women with PCOS generally have a higher rate of stress on their workplace compared to patients with obesity with or without PCOS, while the highest rate of stress at home is observed in obese PCOS patients (Table 5). The difference in results however did not reach statistical significance.

able 5. Stress

\begin{tabular}{|c|c|c|c|}
\hline \multicolumn{4}{|c|}{ Do you have stress on your workplace? } \\
\hline & $\begin{array}{l}\text { Group } 1 \\
\text { Obese }\end{array}$ & $\begin{array}{l}\text { Group } 2 \\
\text { Nonobese PCOS }\end{array}$ & $\begin{array}{l}\text { Group } 3 \\
\text { Obese PCOS }\end{array}$ \\
\hline Yes & $62.1 \%$ & $65.3 \%$ & $60.0 \%$ \\
\hline No & $37.9 \%$ & $34.7 \%$ & $40.0 \%$ \\
\hline \multicolumn{4}{|c|}{ Do you have stress at home? } \\
\hline Yes & $28.6 \%$ & $30.6 \%$ & $45.0 \%$ \\
\hline No & $71.4 \%$ & $69.4 \%$ & $55.0 \%$ \\
\hline
\end{tabular}

Obesity, arterial hypertension, dislipidemia, smoking and stress are among the main factors for development of cardiovascular diseases $[9,10,11,12]$. Despite that the patients diagnosed with PCOS are mostly young and the rate of cardiovascular diseases is increased dramatically after menopause [13], the measures focused on prevention of such diseases 
are most effective when started long before the clinical presentation. This is the reason why the knowledge of these risk factors is of great importance. The aim of the present study was to asses how informed the patients with PCOS and/or obesity are about their body weight, presence of obesity, arterial hypertension and dislipidemia.

After comparing the declared by the patient with the measured weight the highest rate of matching was found in nonobese PCOS group and the lowest in obese PCOS group. The fact that nonobese PCOS patients have the most real perception about their actual weight could be explained by the reluctance of obese women to measure their weight or to share the results with others. We prefer the first hypothesis because $25 \%$ of the obese PCOS patients stated that they don't know their present weight.

Many of the women with obesity with or without PCOS have dislipidemia without knowing that and their rate is higher in obese without PCOS group probably because of the higher mean age of these patients. These data suggest that obese women should be tested for dislipidemia even before menopause [14] and to be informed abut the risks and possibilities for prevention. As for arterial hypertension, in the study population there was lower rate and better knowledge than dislipidemia. Many women however were unable to report their actual blood pressure and to decide if it is appropriate for them.

Other similar studies also show unsatisfactory awareness of different cardiovascular risk factors as only $28.3 \%$ of the participants were able to answer all of the questions about cardiovascular risk [15]. Most of these studies included older postmenopausal women. We were not able to find other studies with PCOS women in this aspect. Having in mind that PCOS has been recognized as a high risk population for diabetes $[5,6,7]$ all diabetes prevention strategies have to be applied for PCOS women.

\section{CONCLUSION}

1. We found satisfactory awareness of women for the presence of cardiovascular risk factors, except form dislipidema.

2. Nonobese PCOS women have the most real perception about their body weight.

3. Many of the patients with obesity with or without PCOS have dislipidemia without knowing about that.

\section{CONSENT}

All authors declare that written informed consent was obtained from the patient for publication of this paper.

\section{ETHICAL APPROVAL}

Authors obtained ethics committee approval for the study

\section{COMPETING INTERESTS}

Authors declare that no competing interests exist. 


\section{REFERENCES}

1. Diamanti-Kandarakis E, Kouli CR, Bergiele AT, Filandra FA, Tsianateli TC, Spina GG. et al. A survey of the polycystic ovary syndrome in the Greek island of Lesbos: hormonal and metabolic profile. J Clin Endocrinol Metab; 1999;84(11):4006-11.

2. Knochenhauer ES, Key TJ, Kahsar-Miller M, Waggoner W, Boots LR, Azziz R. Prevalence of the polycystic ovary syndrome in unselected black and white women of the southeastern United States: a prospective study. J Clin Endocrinol Metab; 1998;83(9):3078-82.

3. Hart R, Hickey M, Franks S. Definitions, prevalence and symptoms of polycystic ovaries and polycystic ovary syndrome. Best Pract Res Clin Obstet Gynaecol. 2004;18(5):671-83.

4. Dahlgren E, Janson PO, Johansson S, Lapidus L, Odén A. Polycystic ovary syndrome and risk for myocardial infarction: evaluated from a risk factor model based on a prospective population study of women. Acta Obstet Gynecol Scand; 1992;71:599-604

5. Lindström J. et al. Take action to prevent diabetes-the IMAGE toolkit for the prevention of type 2 diabetes in Europe. Horm Metab Res. 2010;42 Suppl 1:S37-55.

6. American Diabetes Association. Standards of medical care in diabetes - 2012. Diabetes Care. 2012; 35 Suppl 1:S11-63

7. Gambineri A, Patton L, Altieri P, Pagotto U, Pizzi C, Manzoli L, et al. Polycystic Ovary Syndrome Is a Risk Factor for Type 2 Diabetes: Results From a Long-Term Prospective Study. Diabetes. 2012: in press

8. The Rotterdam ESHRE/ASRM- Sponsored PCOS consensus workshop group. Revised 2003 consensus on diagnostic criteria and long-term health risks related to polycystic ovary syndrome. Fertil Steril. 2004;81:19-25

9. Kitler ME. Differences in men and women in coronary artery disease, systemic hypertension and their treatment. Am J Cardiol. 1992;70:1077-1080.

10. Manolio TA, Pearson TA, Wenger NK, Barrett-Connor E, Payne GH, Harlan WR. Cholesterol and heart disease in older persons and women: review of an NHLBI workshop.Ann Epidemiol. 1992;2:161-176

11. Mosca L, Manson JE, Sutherland SE, Langer RD, Manolio T, Barrett-Connor E. Cardiovascular disease in women: a statement for healthcare professionals from the American Heart Association. Circulation. 1997;96:2468-2482

12. Rich-Edwards JW, Manson JE, Hennekens $\mathrm{CH}$, Buring JE. The primary prevention of coronary heart disease in women. N Engl J Med. 1995;332:1758-1766

13. Kannel WB, Wilson PW. Risk factors that attenuate the female coronary disease advantage. Arch Intern Med. 1995;155:57-61.

14. Canadian Cardiovascular Society position statement. Recommendations for the diagnosis and treatment of dyslipidemia and prevention of cardiovascular disease. Can J Cardiol 2006;22(11).

15. Society for Cardiovascular Angiography and Interventions (SCAI). Scientific Sessions. Baltimore. C 026 Martis N, Wang H, Couri M, Mungee S. Women Heart Health Initiative: Taking the Awareness Issue to the Women and Their Gynecologists. 2011.

(c) 2013 Gateva and Kamenov; This is an Open Access article distributed under the terms of the Creative Commons Attribution License (http://creativecommons.org/licenses/by/3.0), which permits unrestricted use, distribution, and reproduction in any medium, provided the original work is properly cited.

Peer-review history:

The peer review history for this paper can be accessed here: http://www.sciencedomain.org/review-history.php?iid=163\&id=12\&aid=753 